Article

\title{
A Study on Millimetre-Wave Tunable Bandpass Filter Based on Polymer Cap Deflection
}

\section{Seonho Seok *, Janggil Kim, Nathalie Rolland and Paul-Alain Rolland}

IEMN CNRS 8520/Cité Scientifique-Avenue Poincare BP 60069, 59652 Villeneuve d'Ascq Cedex, France; E-Mails: janggil.kim@iemn.univ-lille1.fr (J.K.); nathalie.rolland@iemn.univ-lille1.fr (N.R.); paul-alain.rolland@iemn.univ-lille1.fr (P.R.)

* Author to whom correspondence should be addressed; E-Mail: seonho.seok@iemn.univ-lille1.fr; Tel.: +33-3-2019-7921; Fax: +33-3-2019-7896.

Received: 29 November 2011; in revised form: 28 December 2011 / Accepted: 29 December 2011/ Published: 6 January 2012

\begin{abstract}
This paper presents a new tuning mechanism for millimetre-wave BPF based on deflection of the $\mathrm{BCB}$ membrane of $\mathrm{BCB}$ packaging cap. A 3-pole parallel-coupled microstrip filter operating at $60 \mathrm{GHz}$ is first implemented on $30 \mu \mathrm{m}$-thick BCB polymer substrate and then BCB-capped through our new anti-adhesion layer assisted wafer-level transfer technique. Gold electrodes are fabricated on top of the BCB cap for DC actuation. The implemented BCB capped BPF showed the tuning range of $1.49 \mathrm{GHz}$ from $63.36 \mathrm{GHz}$ to $64.85 \mathrm{GHz}$ with the associated insertion losses of $-9.7 \mathrm{~dB}$ and $-9.4 \mathrm{~dB}$ and the return losses better than $-11 \mathrm{~dB}$ over the tuning range.
\end{abstract}

Keywords: BCB polymer; filter; tuning; millimeter-wave

\section{Introduction}

For millimeter wave circuits, MEMS technology is attracting an increased interest due to its merits as enabling technology by emerging novel circuits such as transmission lines with low loss and low dispersion, radio frequency (RF) filter, voltage controlled oscillator and phase shifters [1-3]. The mature micromachining technology makes it possible to implement microwave and millimeter-wave filters on dielectric membrane suitable to on-chip integration. MEMS varactor is common to give a tuning capability to filter, but there still exist some barriers due to its reliability and packaging issues [4]. As an alternative way, flexible polymer substrate can be utilized for widely tunable resonator as reported by 
Chappell et al. [5] and ferrite tunable bandpass filter is also presented for 40-60 GHz band [6]. Likewise, a movable dielectric membrane can be a candidate to realize a tunable filter at millimeter-wave frequencies because it changes the electromagnetic field distribution of the packaged filter. BCB cap packaging was demonstrated in our previous work [7]. Starting with this packaging cap, gold electrodes are fabricated on top of it to realize a capacitive actuator with counter-electrodes on the filter substrate. Therefore, the BCB membrane of the BCB cap can be actuated by electrostatic force applied to the electrodes. As the BCB cap goes down to the microstrip element of the filter, its characteristic impedance decreases, resulting in the increase of effective dielectric constant. In this paper, $60 \mathrm{GHz}$-band tunable parallel-coupled $\mathrm{BPF}$ is presented using BCB cap deflection. In Section 2, the concept of the tunable filter is first described and then the parallel-coupled BPF (Band Pass Filter) design method will be presented with analytical calculation and electromagnetic simulation. In addition, the tunable characteristic will be also investigated as a function of air gap height between BCB cap and filter. The fabrication process for the designed filter will be explained in Section 3. In Section 4, characterization and discussion will be presented.

\section{Concept and Design}

Figure 1 shows the cross section of the proposed tunable filter. It has a planar filter and lower tuning electrodes on BCB substrate having ground plane backside. BCB cap is introduced as a tuning element and upper tuning electrodes are made on top of the BCB cap. The air-gap of the BCB cap is decreased due to the electrostatic force between the upper and lower tuning electrodes.

Figure 1. Cross-section of the proposed tunable bandpass filter.

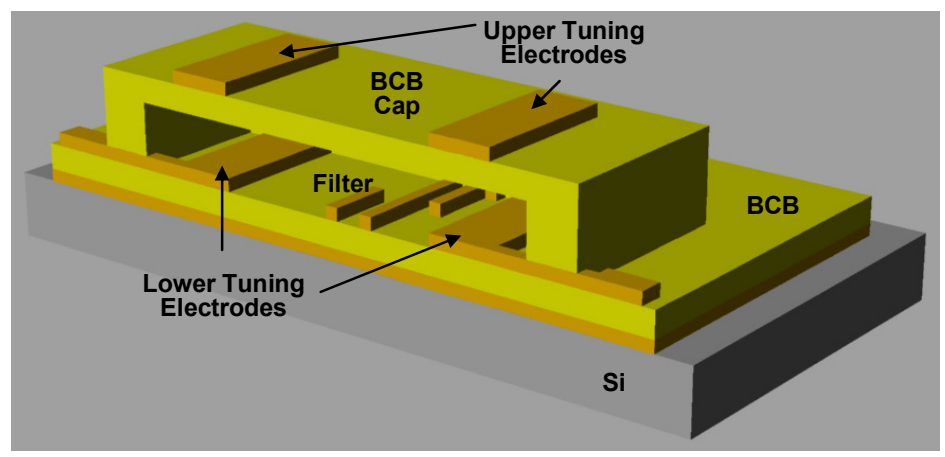

The planar filter is first designed as follows; a parallel-coupled, half-wavelength resonator filter as shown in Figure 2 is first designed following standard design procedure in [8]. The 3-pole, 5\% bandwidth and $0.1 \mathrm{~dB}$ ripple at mid-band $f_{0}=60 \mathrm{GHz}$ were used to find $\mathrm{g}$ value for a low pass prototype and the material properties of the $\mathrm{BCB}$ material are given as 3 for dielectric constant and 0.001 for loss tangent. BCB substrate thickness is $30 \mu \mathrm{m}$. At first, even and odd mode impedances between the two resonators were analytically calculated as listed in Table 1(a). Half of them are given due to the symmetry of the filter. The next step is to find the actual dimensions of the coupled resonators corresponding to the desired even- and odd-mode impedance. Using design equations of the coupled resonators given in Chapter 4 of [7], the width and spacing for each pair of the resonator are found as Table 1(b). With the physical dimensions, electromagnetic simulation has been performed to examine and optimize the frequency response of the filter. Given with the designed filter, tuning 
characteristic using BCB cap actuation was investigated by changing the air gap height from $2.5 \mu \mathrm{m}$ to $15 \mu \mathrm{m}$ as shown in Figure 3. The tuning range was $1.6 \mathrm{GHz}$ between $60.6 \mathrm{GHz}$ at $2.5 \mu \mathrm{m}$ air gap height and $62.2 \mathrm{GHz}$ at $15 \mu \mathrm{m}$ with the corresponding insertion losses of $-3.29 \mathrm{~dB}$ and $-3.34 \mathrm{~dB}$ and return loss better than $-15 \mathrm{~dB}$. Also, the behaviour of $\mathrm{BCB}$ membrane is investigated as a function of actuation voltage. The dimension of DC electrode is $2,760 \mu \mathrm{m}(\mathrm{L}) \times 900 \mu \mathrm{m}(\mathrm{W})$. The capacitive electrostatic actuator is modeled and simulated using ANSYS program. The deflection of BCB cap at $100 \mathrm{~V}$ of the DC actuation voltage is shown in Figure 4(a). The relationship between BCB cap deflection and DC actuation voltage is shown in Figure 4(b). It is found that maximum deflection of $14 \mu \mathrm{m}$ has been achieved at $200 \mathrm{~V}$. Note that the model does not include the BCB residual stress and the effect of the gold electrodes on BCB cap. Therefore, the actual DC actuation voltage will be higher than the expected one.

Figure 2. Typical parallel-coupled bandpass filter.

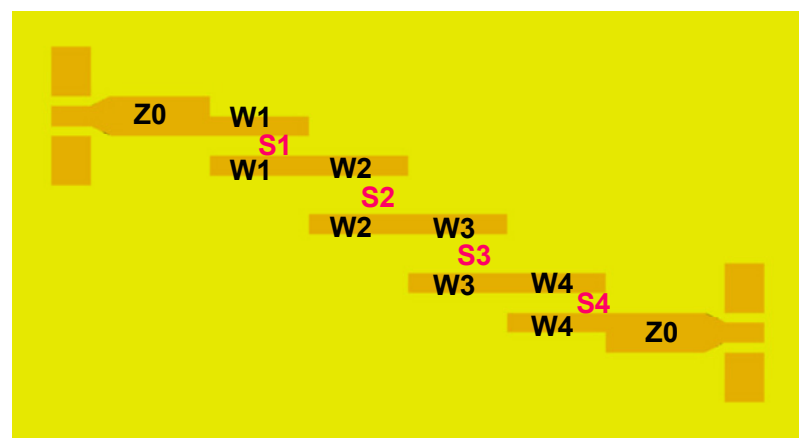

Table 1. Design parameters of the bandpass filter. (a) Even- and odd-mode impedance of coupled microstrip lines. (b) Coupled microstrip dimensions of the filter.

\begin{tabular}{|c|c|c|}
\hline $\mathrm{j}$ & $\left(\mathrm{Z}_{\mathrm{oe}}\right)_{\mathrm{j}, \mathrm{j}+1}$ & $\left(\mathrm{Z}_{\mathrm{oo}}\right)_{\mathrm{j}, \mathrm{j}+1}$ \\
\hline 0 & 67.6 & 40 \\
\hline 1 & 53.9 & 46.7 \\
\hline
\end{tabular}

(a)

\begin{tabular}{|c|c|c|}
\hline $\mathrm{j}$ & $\mathrm{W}_{\mathrm{j}}(\mu \mathrm{m})$ & $\mathrm{S}_{\mathrm{j}}(\mu \mathrm{m})$ \\
\hline 1 and 4 & 70 & 10 \\
\hline 2 and 3 & 80 & 60 \\
\hline
\end{tabular}

(b)

Figure 3. Filter tuning simulation result as a function of air-gap height.

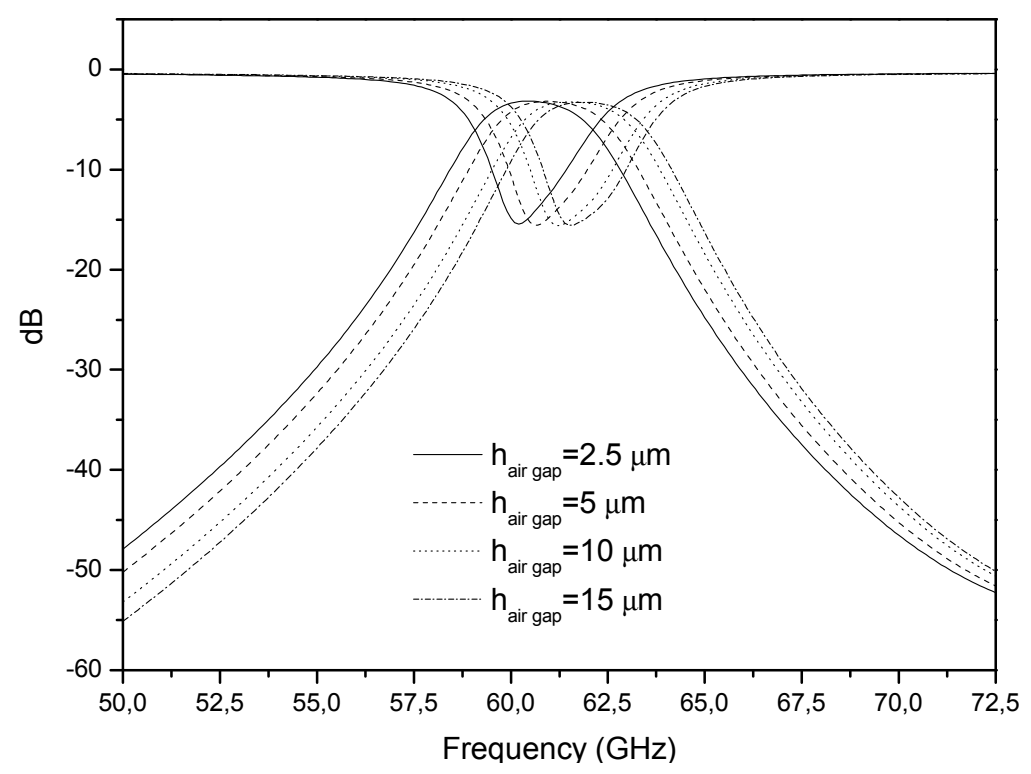


Figure 4. BCB cap deflection simulation results. (a) BCB cap deflection when DC actuation voltage is $100 \mathrm{~V}$. (b) BCB cap deflection as a function of actuation voltage.

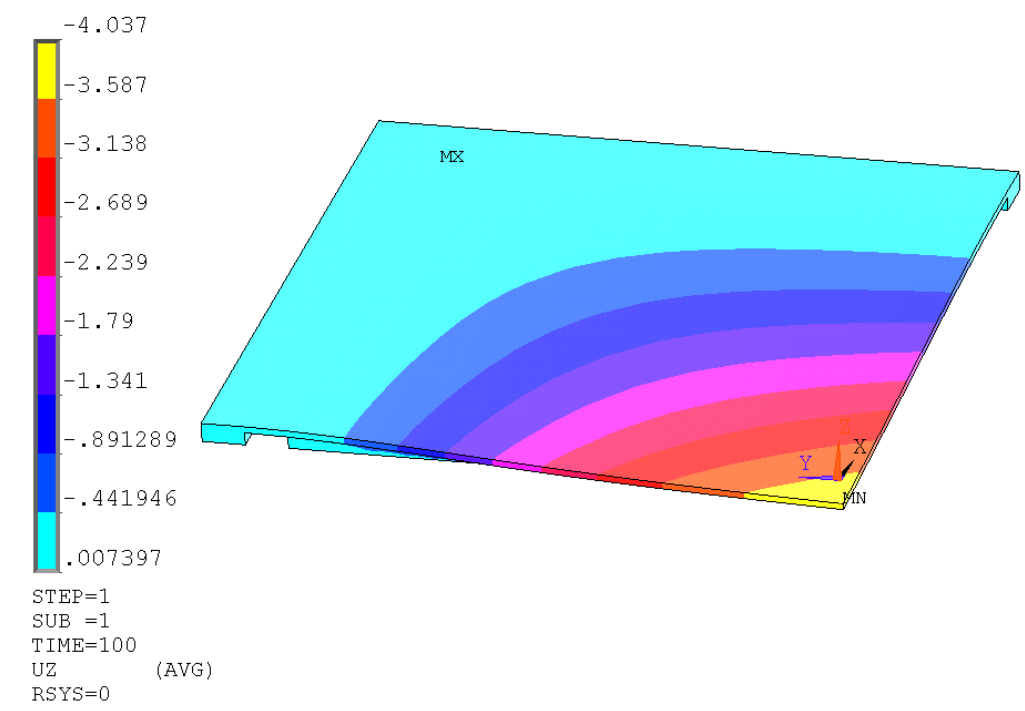

(a)

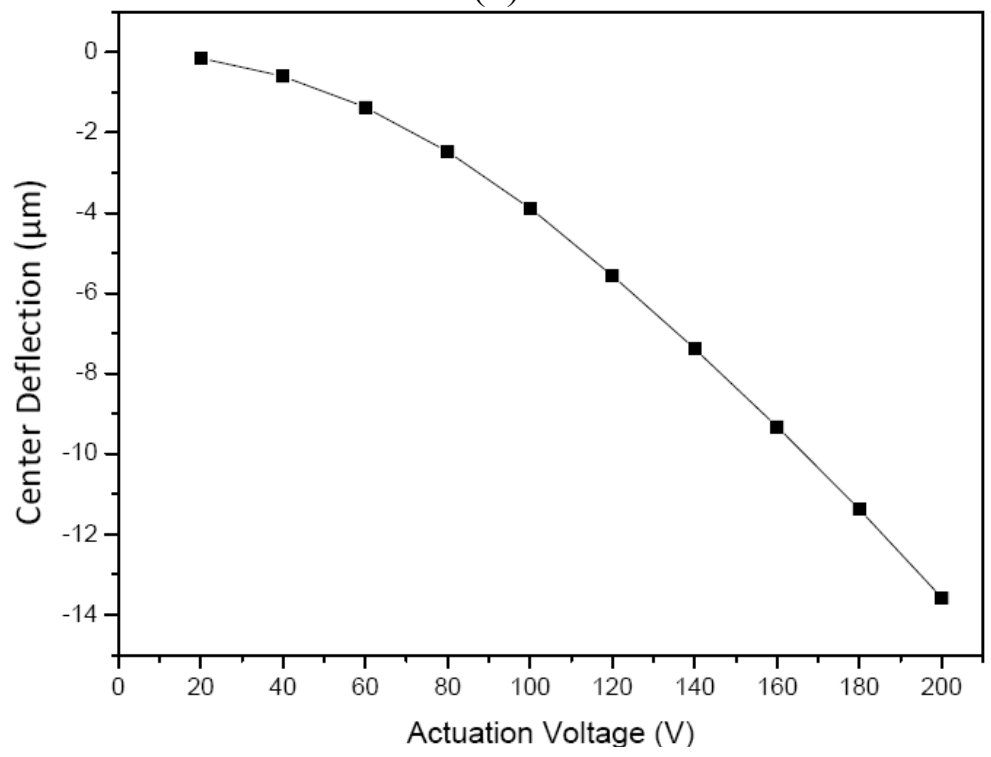

(b)

\section{Fabrication}

Figure 5 depicts the fabrication process flow of the proposed tunable filter; (a) $30 \mu$ m-thick BCB substrate with vias is formed on $2 \mu \mathrm{m}$-thick gold ground plane using photopatternable BCB multi-layer coating that is already reported in our previous work [4]. It provides $15 \mu \mathrm{m}$-thick single BCB layer after hard-curing at $250{ }^{\circ} \mathrm{C}$ for 60 minutes. (b) Gold electroplating is carried out to fabricate the designed filter and vias to ground plane. (c) BCB caps are transferred to the filter substrate using our anti-adhesion layer assisted transfer technique. The details can be found in [9]. (d) Top electrodes of capacitive actuators for DC actuation are formed using gold electroplating. The thickness is $1.5 \mu \mathrm{m}$. It should be noted that all of the gold electroplating are carried out using AZ9260 PR mold. 
Figure 5. Fabrication process flow.

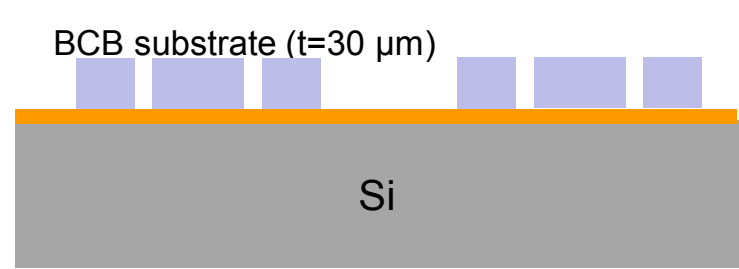

(a)

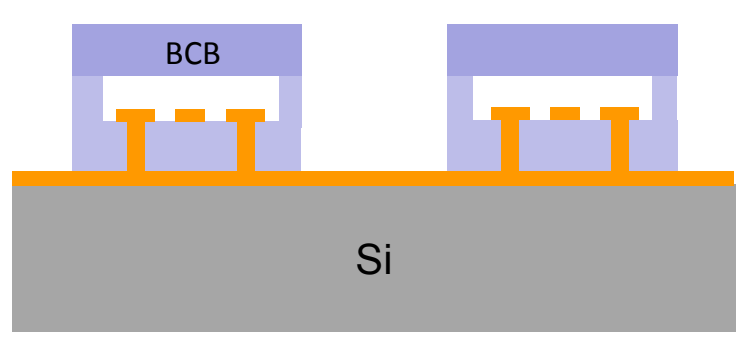

(c)

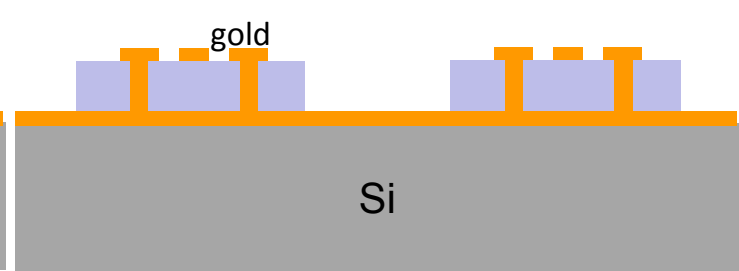

(b)

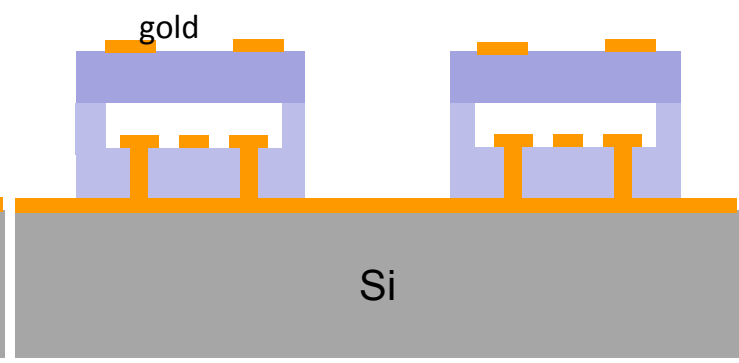

(d)

Figure 6 shows the fabricated BCB capped tunable filter. A planar filter on BCB substrate, BCB cap, and tuning electrodes on top of $\mathrm{BCB}$ cap are successfully implemented. Figure 6(b) shows the intentionally destroyed $\mathrm{BCB}$ cap to show the lower tuning electrodes placed at both sides of the planar filter. It should be noted that the upper tuning electrode was made on top of BCB cap instead of BCB cap inside due to the technological advantage. However, it is the reason why it needs such a high DC actuation voltage as mentioned earlier.

Figure 6. Fabricated tunable filter.

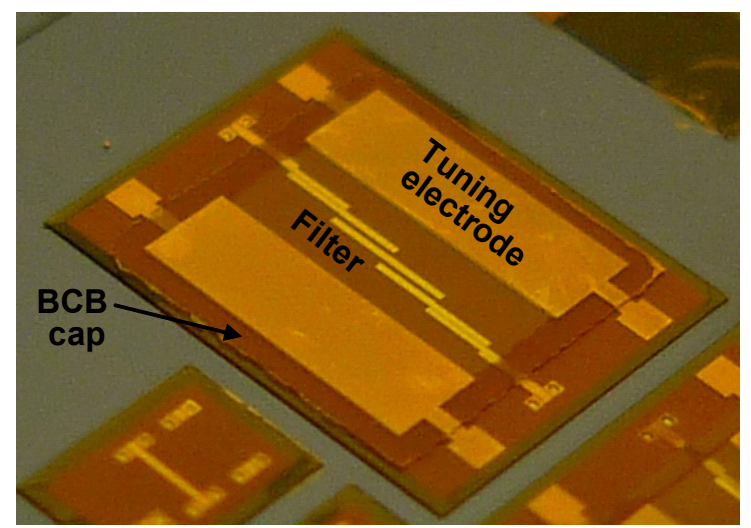

(a)

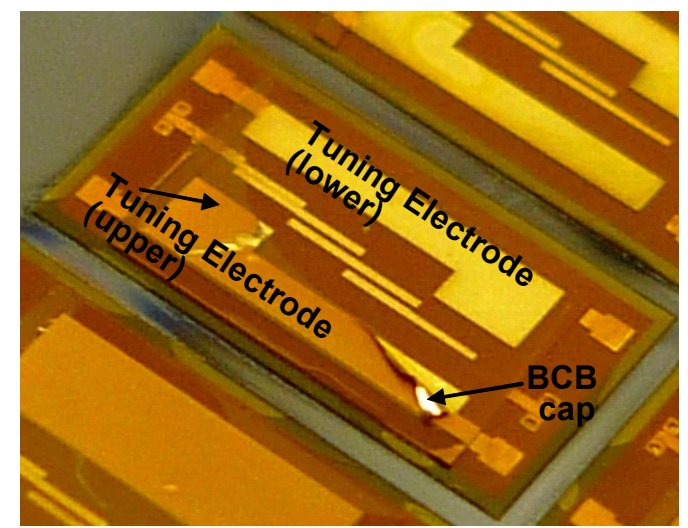

(b)

In general, BCB cap has downward deflection due to its tensile residual stress as presented in [9]. As a reference, a BCB cap profile without gold electrode is given in Figure 7(b). The BCB cap profile of the fabricated tunable filter is investigated because it determines the behaviour of the BCB cap actuation. As shown in Figure 7, the BCB membrane has $5 \mu \mathrm{m}$ upward deflections at its center due to the residual stress effect between BCB cap and upper gold electrodes. 
Figure 7. BCB cap profiles with and without upper tuning electrodes. (a) Measured BCB cap profile after upper tuning electrodes fabrication. (b) Measured BCB cap profile without upper tuning electrodes.

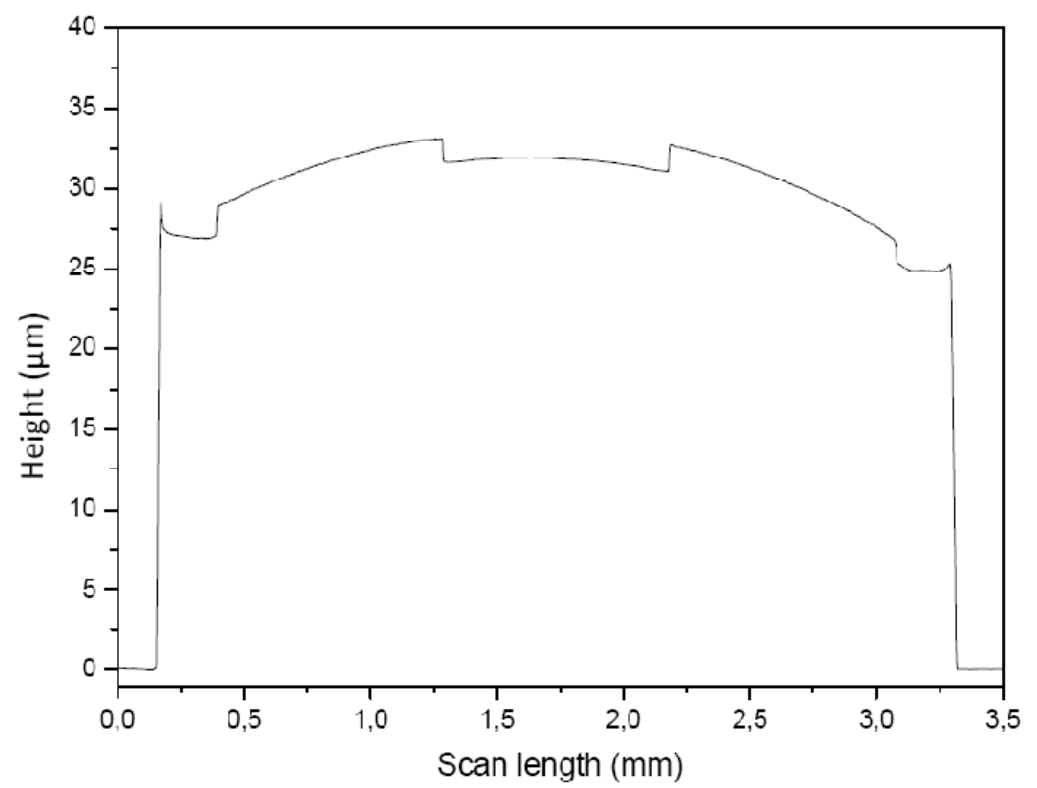

(a)

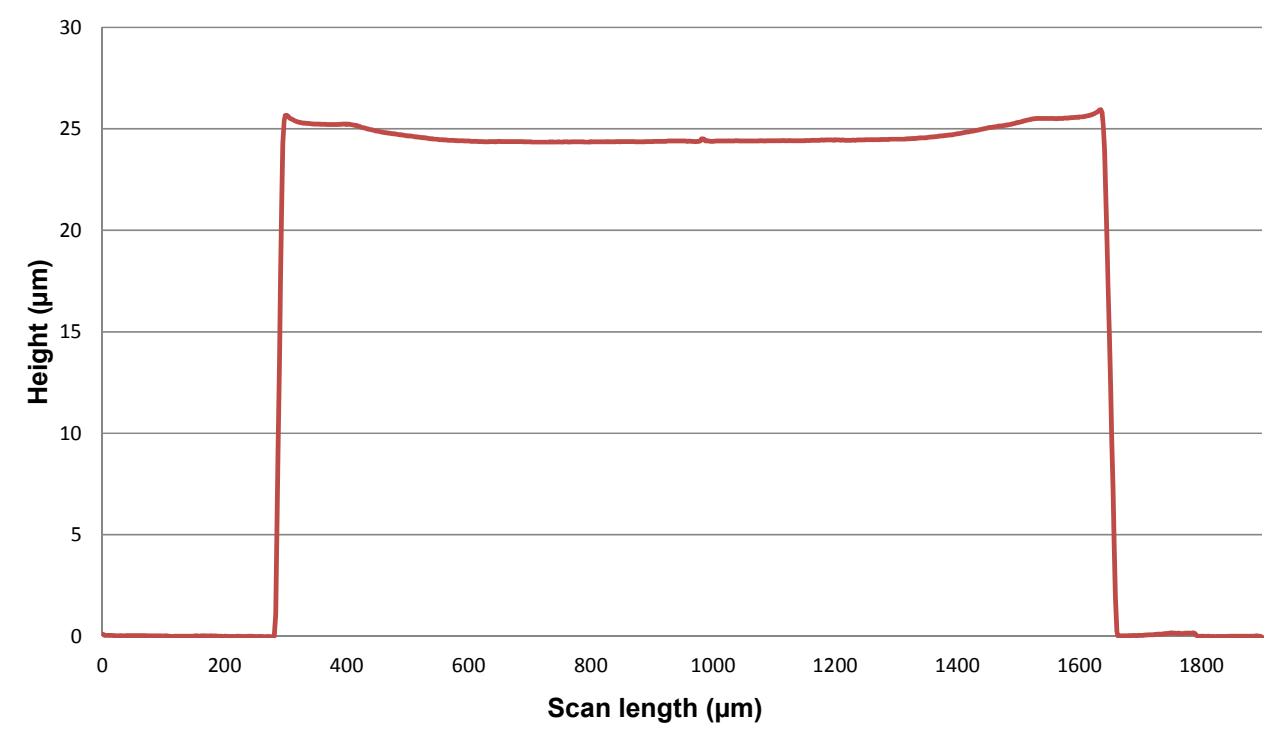

(b)

\section{Characterizations and Discussions}

The manufactured BPF on BCB substrate without BCB cap was first characterized by HP8510C and probe system. The measured insertion loss and return loss of are shown in Figure 8. The insertion loss and the return loss were $-8.7 \mathrm{~dB}$ and less than $-10 \mathrm{~dB}$ including probe-to-probe loss within passband centered at $65.64 \mathrm{GHz}$. The discrepancy between measurement and simulation is mainly resulted from fabrication process errors on the thickness of BCB substrate and the defined gaps between the couple microstrip lines. Through the ADS and momentum modeling based on the measurement, it is found that the insertion loss and the return loss of the filter are sensitive to the gaps S2 and S3 which will be included into the new filter design. 
The two different air gap heights of BCB cap at $0 \mu \mathrm{m}$ and $15 \mu \mathrm{m}$ resulted in the center frequencies of $64.85 \mathrm{GHz}$ and $63.36 \mathrm{GHz}$ respectively having the tuning range of $1.49 \mathrm{GHz}$, and the associated insertion losses are $-9.4 \mathrm{~dB}$ and $-9.7 \mathrm{~dB}$ while the return losses are better than $-11 \mathrm{~dB}$. To enhance the tunability, other polymer material with higher dielectric material or mixture of dielectric and $\mathrm{BCB}$ polymer cap will be taken into account.

Figure 8. Measured tuning characteristic of the BCB capped tunable filter5. (a) Insertion loss. (b) Return loss.

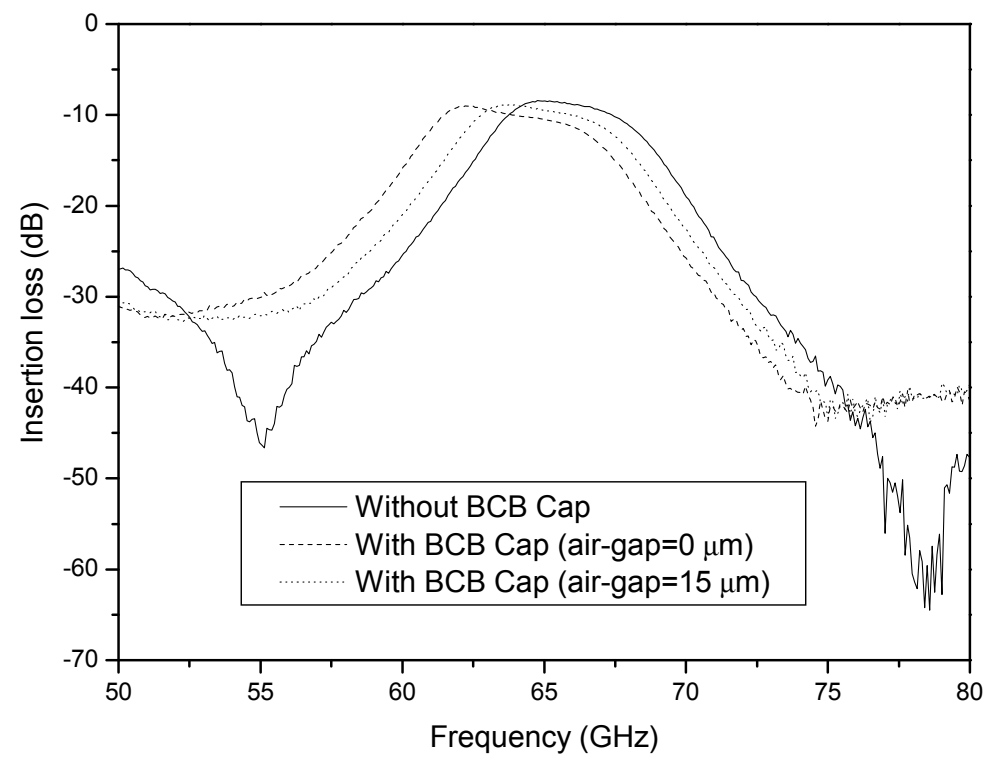

(a)

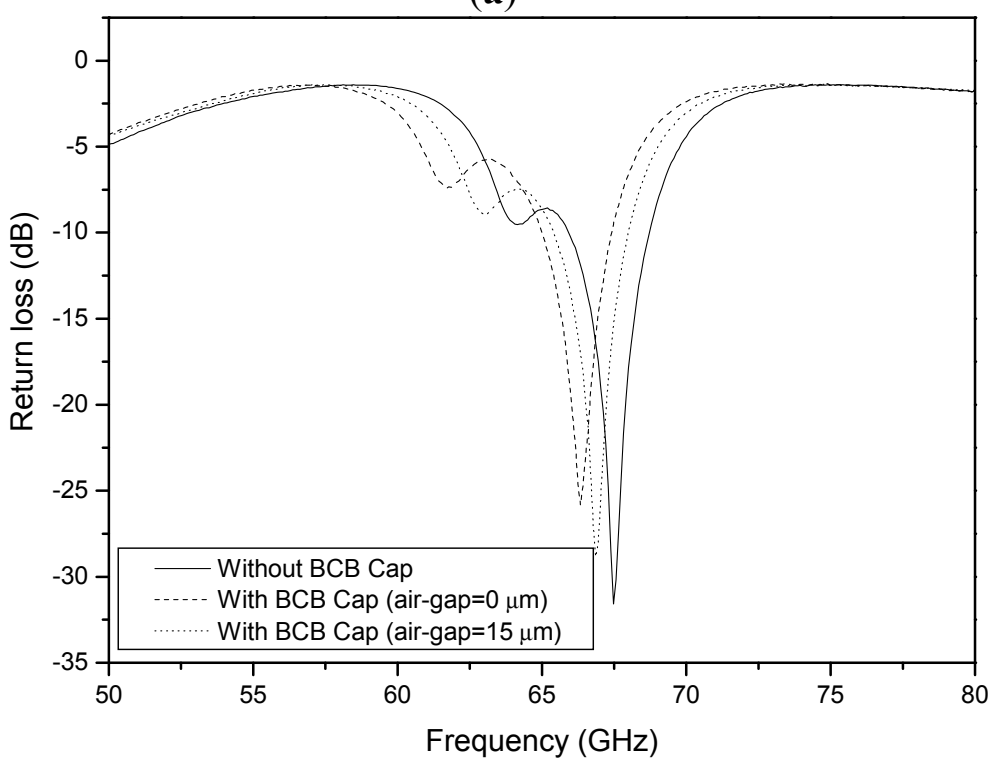

(b)

\section{Conclusions}

For a tunable filter at millimeter-wave frequency, dielectric actuation method is proposed as an alternative way of current MEMS varactor ones. Because dielectric actuation changes the electromagnetic field distribution of the filter, it can tune the center frequency of the filter. BCB dielectric cap placed above the filter like a package cap has been adopted as a tuning element as 
MEMS varactor and it will be actuated by electrostatic force varying the air-gap between BCB cap and the filter element. The BCB cap is successfully transferred to the filter device by BCB thin-film cap transfer technology. The $\mathrm{BCB}$ cap actuation showed the $1.49 \mathrm{GHz}$ frequency tuning from $64.85 \mathrm{GHz}$ to $63.36 \mathrm{GHz}$ with an air-gap change of $15 \mu \mathrm{m}$. Therefore, the influence of BCB dielectric to filter tuning was verified and further investigation on tuning will be performed as a function of air-gap height as well as actuation voltage.

\section{Acknowledgments}

The authors wish to acknowledge the technical staff members of IEMN in France. The presented work is part of MEMSPACK, a collaboration between IMEC, VTT, FhG-ISiT, University of Perugia, FBK institute, IEMN-CNRS and MEMS TC (www.memspack.eu). MEMSPACK receives financial support in the EC FP7 program under grant agreement No. 223882.

\section{References}

1. Baker, N.S.; Rebeiz, G.M. Distributed MEMS True-Time Delay Phase Shifters and Wide-Band Switches. IEEE Trans. Microwave Theory 1999, 46, 299-302.

2. Weller, T.M.; Katehi, L.P.B.; Rebeiz, G.M. High Performance Microshield Line Components. IEEE Trans. Microwave Theory 1995, 43, 534-543.

3. Kudrle, T.D.; Neves, H.P.; Rodger, D.C.; MacDonald, N.C. A Microactuated Millimeter Wave Phase Shifter. In Proceedings of Solid-State Sensor and Actuator Workshop, Digest Tech, Sendai, Japan, 7-10 June 1999; pp. 1276-1279.

4. Seok, S.; Rolland, N.; Rolland, P.A. Packaging Methodology for RF Devices Using a BCB Membrane Transfer Technique. J. Micromech. Microeng. 2006, 2384-2388.

5. Hajela, S.; Gong, X.; Chappell, J.W. Widely Tunable High-Q Evanescent-Mode Resonators Using Flexible Polymer Substrates. In Proceedings of 2005 IEEE MTT-S International Microwave Symposium Digest, Long beach, CA, USA, 12-17 June 2005; pp. 2139-2142.

6. Nicolson, D. A High Performance Hexagonal Ferrite Tunable Bandpass Filter for the 40-60 GHz Region. In Proceedings of 1985 IEEE MTT-S International Microwave Symposium Digest, St. Louis, MO, USA, 4-6 June 1985; pp. 229-232.

7. Kim, J.; Seok, S.; Rolland, N.; Rolland, P.A. A Novel Wafer Level Bonding/Debonding Technique Using an Anti-adhesion Layer for Polymer-based 0-level Packaging of RF device. In Proceedings of The 60th Electronic Components and Technology Conference (ECTC 2010), Las Vegas, NV, USA, 1-4 June 2010; pp. 323-328.

8. Hong, J.S.; Lancaster, M.J. Microstrip Filters for RF/Microwave Applications 2001; John Wiley \& Sons, Inc.: New York, NY, USA.

9. Seok, S.; Rolland, N.; Rolland, P.A. A Theoretical and Experimental Study of BCB Thin-Film Cap Zero-Level Package Based on FEM Simulations. J. Micromech. Microeng. 2010, doi:10.1088/0960-1317/20/9/095010.

(C) 2012 by the authors; licensee MDPI, Basel, Switzerland. This article is an open access article distributed under the terms and conditions of the Creative Commons Attribution license (http://creativecommons.org/licenses/by/3.0/). 